Bond University

Research Repository

\title{
Bong
}

\section{Anaemia in patients undergoing major bowel surgery - Prevalence and current practice: A public and private institution experience}

Poon, Edgar; Pache, David; Delaforce, Alana; Abdalla, Lemya; McGuire, Treasure

Published in:

Journal of Perioperative Practice

DOI:

$10.1177 / 1750458920934321$

Licence:

Other

Link to output in Bond University research repository.

Recommended citation(APA):

Poon, E., Pache, D., Delaforce, A., Abdalla, L., \& McGuire, T. (2021). Anaemia in patients undergoing major bowel surgery - Prevalence and current practice: A public and private institution experience. Journal of Perioperative Practice, 31(6), 215-222. https://doi.org/10.1177/1750458920934321

\section{General rights}

Copyright and moral rights for the publications made accessible in the public portal are retained by the authors and/or other copyright owners and it is a condition of accessing publications that users recognise and abide by the legal requirements associated with these rights.

For more information, or if you believe that this document breaches copyright, please contact the Bond University research repository coordinator 
1 Anaemia in patients undergoing major bowel surgery - prevalence and current

2 practice: a public and private institution experience

3 Edgar Poon ${ }^{1 *}$, David Pache ${ }^{1,2,4}$, Alana Delaforce ${ }^{3,5}$, Lemya Abdalla ${ }^{6}$, Treasure McGuire ${ }^{1,2,4}$

$4 \quad{ }^{1}$ School of Pharmacy, The University of Queensland, Woolloongabba, QLD, Australia

$5 \quad{ }^{2}$ Mater Pharmacy, Mater Health, Brisbane, QLD, Australia

$6 \quad{ }^{3}$ Clinical Governance, Mater Health, Brisbane, QLD, Australia

$7 \quad{ }^{4}$ Faculty of Health Sciences and Medicine, Bond University, Gold Coast, QLD, Australia

$8{ }^{5}$ School of Nursing and Midwifery, University of Newcastle, Newcastle, NSW, Australia

$9 \quad{ }^{6}$ Geriatric \& General Medicine, Mater Health, Brisbane, QLD, Australia

10

11

12

13

14

Edgar Poon

David Pache

Alana Delaforce

Lemya Abdalla

Treasure McGuire

${ }^{*}$ Correspondence:

Edgar Poon

Email: e.poon@uq.net.au

Email address

e.poon@uq.net.au

d.pache@uq.edu.au

Alana.Delaforce@ma

Lemya.Abdalla@mater.org.au 0000-0001-6972-9084

t.mcguire@uq.edu.au

\section{ORCID no.}

0000-0001-8564-956X

$0000-0001-5120-9806$

$\underline{0000-0003-1417-7037}$
20

Keywords: iron, anaemia, blood management, blood transfusion, preoperative period 


\section{Abstract}

23 Aim The study aimed to compare the frequency and alignment of preoperative anaemia screening and

24 treatment with Australian guidelines in elective bowel surgery and determine the impact on clinical 25 outcomes.

26 Methods We performed a retrospective observational study, with an audit of 559 adult patients who

27 underwent major elective bowel surgery in an Australian metropolitan hospital, January 2016 to

28 December 2018. Outcome measures included rate of anaemia, guideline compliance, hospital length

29 of stay and transfusion rate.

30 Results Preoperative anaemia assessment occurred in $82.6 \%$ of patients. However, only $5.2 \%$ received

31 recommended biochemical tests at least one week before surgery. Only $25.2 \%$ of anaemic patients

32 received preoperative treatment; they experienced a longer hospital length of stay (LOS) (9.93 days vs

337.88 days, $\mathrm{p}<0.001)$ and an increased rate of transfusion (OR: $3.186, \mathrm{p}<0.05)$.

34 Conclusion The gaps between current preoperative anaemia screening, management, and national 35 guidelines, may place patients at higher risk of poor surgical outcome. 
Preoperative anaemia is common in patients undergoing bowel surgery and is a predictor of poor surgical outcomes, including increased hospital LOS, morbidity and health expenditure (Michailidou \& Nfonsam 2018, Shander et al 2012). These adverse outcomes may be avoided if anaemia is addressed in the preoperative setting. This highlights the need for timely anaemia assessment and prompt treatment in the preoperative setting.

Patient Blood Management (PBM) is an approach designed to optimise factors associated with blood loss in the perioperative setting, potentially reducing the incidence of unnecessary transfusion and improving patient outcomes (Society for the Advancement of Blood Management (SABM) 2019). The current PBM model consists of three pillars: optimising red blood cell mass, minimising blood loss, and managing anaemia (SABM 2019). Healthcare facilities that endorse this strategy have reported significant improvement in surgical outcomes and reduced hospital costs (Leahy et al 2017). For these reasons, the National Safety and Quality in Health Care Standards (NSQHC) mandate that hospitals embed PBM in their provision of clinical care; and healthcare providers are encouraged to form multidisciplinary teams to determine how PBM can be effectively incorporated into local practices (Australian Commission on Safety and Quality in Health Care 2017, Delaforce et al 2018).

Since anaemia management is part of PBM, treatment should be commenced on diagnosis, and consideration given to delaying the surgery, if feasible, to minimise the risk of poor surgical outcomes (National BloodAuthority (NBA) 2012). Traditionally, oral iron supplementation is indicated if iron deficiency, with or without anaemia, is confirmed. However, its use is limited by patient complaints of gastrointestinal side effects and the poor bioavailability of iron salts, especially in those with bowel conditions (Leal-Noval et al 2013, Madrazo-González et al 2011, Weiss \& Goodnough 2005). Intravenous (IV) iron has been proposed as a superior alternative since it bypasses the gastrointestinal tract, ensuring a 100\% bioavailability and a better side effect profile (Baird-Gunning \& Bromley 
2016, Girelli et al 2018). However, the increasing use of iron infusion has led to reports of rare, but severe hypophosphataemia and permanent skin discolouration, associated with either iron's pharmacology or the process of administration (Chen et al 2019, Harris et al 2018).

To maintain high-quality patient care, healthcare facilities need to examine the level of alignment between their hospital performance and the national PBM guidelines. Work is currently being undertaken at our health facility, in order to identify alignment gaps and develop a robust improvement plan. Other facilities have applied auditing methods to assist in revealing gaps in practice, including a 2015 Australian study involving hospitals in most states which indicated the quality of anaemia screening and treatment remains suboptimal (Department of Health and Human Services Victoria (DHHSV), Blood Matters (BM) 2016). The study revealed only $32 \%$ of patients are receiving timely preoperative anaemia assessment that is needed to differentiate the anaemia type, and facilitate appropriate management before surgery. Patients should have at least a full blood count (FBC), ferritin test, and C-Reactive Protein (CRP) at least one week before surgery (DHHSV, BM 2016). Limited Australian data have been published since the 2015 study in the bowel surgery population (Hong et al 2018). As there is a lack of clinical data on the effect of perioperative anaemia in bowel surgery patients and uncertainty around the implementation of PBM in the local setting, close monitoring of current practice is vital to guide PBM implementation and identify areas for improvement. Our study aimed to investigate the compliance of anaemia assessment and treatment in accordance with PBM guidelines at a major metropolitan tertiary care hospital, specifically in patients undergoing bowel surgery, and to find if there was an association between anaemia; length of stay and risk of transfusion.

\section{Methods:}

We conducted an observational, retrospective chart audit at a large Australian metropolitan teaching healthcare facility, with ethical review exemption received from the hospital Human Research Ethics 
Committee (52917-EXMT/MML/52917 (V1)). This pragmatic approach was chosen as it enabled our team to address a clinical question, through cost-effective longitudinal data access in a large population of interest. As health service data were routinely collected without specific a priori research goals, we conducted and reported this research in accordance with the reporting of studies Conducted using Observational Routinely-collected health Data (RECORD) guideline (Benchimol et al 2015).

Inclusion and exclusion criteria: We included both private and public patients aged 18 or older at admission who underwent major elective bowel surgery between January 2016 and December 2018 . We used diagnosis-related group (DRG) codes for major bowel surgery: G01A/B/C and G02A/B/C to assist in patient selection. A team of a surgeon, registered nurse, and pharmacist was formed to assess whether the surgical procedure met the inclusion criteria and minimise any potential DRG coding errors. We excluded patients admitted for emergency surgery or those patients without evidence of preoperative screening. Patients who underwent minor surgery were also excluded as minimal blood loss is anticipated in their surgery, and thus, are less likely to be affected by preoperative anaemia.

An electronic audit tool was developed by the research team, using evidence-based criteria, sourced from both local policy and the PBM Guidelines: Module 2 - Perioperative, published by the NBA (2012). Measures were categorised and collected across the patient's surgical journey (Box 1). Categories measured were deemed integral to appropriate surgical care and blood management. All patient data were de-identified to preserve privacy.

The audit tool was initially piloted for utility, using the electronic medical records of ten patients, to collect demographics, measures and outcomes described in Box1. Two team members independently extracted and recorded the data, with any discrepancies or clarifications resolved, and the tool adjusted prior to data collection. 
The primary study outcome was to determine the proportion of patients who were screened as anaemic, requiring preoperative iron therapy, and did receive it. The questions were developed to assess the level of compliance with PBM Guidelines (2012); and cases were classified using patient haemoglobin $(\mathrm{Hb})$ levels as a primary denominator in anaemia screening. $\mathrm{Hb}$ levels $<130 \mathrm{~g} / \mathrm{L}$ for men and $<120 \mathrm{~g} / \mathrm{L}$ for women were considered anaemic. Further testing results, including ferritin and CRP levels, were used to differentiate the type of anaemia. We also compared our laboratory screening audit results with a 2015 Australian multisite audit which was previously benchmarked against the NBA PBM guidelines (DHHSV \& BM 2016).

Data and statistical analysis:

Data collected were summarised and reported as means for continuous variables, and as proportions for categorical variables. Proportion, log-rank, and unpaired t-tests were used as appropriate. Logistic regression analysis was performed to determine the odds ratio of the testing subjects. Statistical significance was set as a two-tailed $\mathrm{p}$-value $<0.05$. All statistical analysis was performed with $\mathrm{R}$ (version 3.6.1).

Results:

Within the 3-year period, 863 patient records were retrieved from the hospital electronic medical record system. After applying the exclusion criteria, 559 patients were included for audit. Patient characteristics are reported in Table 1 . The majority admitted for bowel surgery were cancer patients (62.6\%), followed by inflammatory or infective bowel disease, including Crohn's disease and ulcerative colitis $(23.1 \%)$, bowel disease $(10.2 \%)$, and ileostomy or colostomy procedure for nonmalignant disease (4.1\%). 
Of these 559 patients, $462(82.6 \%)$ received some preoperative blood testing for anaemia. Of those who were assessed, 310 patients $(67.1 \%)$ were screened less than one week before their surgery. One hundred and thirty-four (29.0\%) patients were assessed 1 week up to 6 weeks and 18 (3.9\%) greater than 6 weeks prior to surgery.

Of the patients who were screened for preoperative anaemia, FBC results were retrieved for 459 (99.4\%). However, other tests that assist in differentiating the type of anaemia were less commonly conducted alongside the FBC; only 51 (11.0\%) patients were assessed for ferritin levels and 92 (19.9\%) had their CRP levels tested. In total, 167 (36.1\%) patients were found to be anaemic in the preoperative setting. However, the majority $(\mathrm{n}=147,88.0 \%)$ were classified to have undifferentiated anaemia, as further results were needed to determine anaemia type. Table 2 shows the screening tests performed and other screening results. When we compared our audit results of screening laboratory parameters with those from the 2015 multi-state audit (Figure 1), the bar graph indicates our healthcare facility was performing comparably in relation to the proportion of FBCs undertaken in the preoperative setting and even better for conduct of renal function tests. However, performance in determining patient anaemia status for the healthcare facility studied, especially ferritin test results (11.0\% versus $31.2 \%$ multi-state audit), was subpar.

Overall, only 42 (25.2\%) patients from the anaemic group received treatment preoperatively, 27 received IV iron, seven took oral iron supplementation and eight had a preoperative transfusion. A small proportion of the non-anaemic patients also received treatment in the preoperative phase, with four receiving IV iron (Table 3).

\section{When comparing the anaemic group with the non-anaemic group, the former had a significantly} higher mean hospital LOS (9.93 days vs 7.88 days, $p<0.001$, Figure 2$)$. They also had a higher perioperative transfusion rate than the non-anaemic group (OR: 3.186, $\mathrm{p}=0.049)$. In addition, anaemic 

patients required more units of blood than the non-anaemic group (2.43 units vs 1.40 units) (Table 4). All of these factors are likely to be associated with higher admission-related costs.

\section{Discussion:}

This longitudinal retrospective audit indicated that preoperative anaemia is commonly assessed in patients undergoing surgery. However, the majority of these assessments did not comply with the NBA PBM guidelines, with only $5.7 \%$ of all patients having the recommended blood tests (at least an FBC, ferritin test and CRP) within the recommended timeframe (at least 1 week before surgery). As preoperative anaemia is a powerful predictor of perioperative transfusion, failure to provide quality anaemia assessment means patients are potentially at risk of preventable suboptimal surgical outcomes, including an increased mortality rate and in-hospital morbidity, which can be further translated into an increased health expenditure (Khanna et al 2003, Goel et al 2018). Anaemic patients should also be screened for anaemia post-surgery, and iron (oral or IV) prescribed if appropriate, with the use of postoperative transfusion limited to patients who reach the restrictive transfusion threshold (Muñoz et al 2018).

Most patients (67.1\%) received anaemia assessment less than 1 week before the surgery: these patients were potentially at a higher risk of poor postoperative outcomes, as the timeframe was insufficient for anaemia to be investigated and treated without delaying surgery. Suboptimal laboratory anaemia evaluations, defined as not having all of the preoperative blood tests recommended by the NBA PBM Guidelines (2012), can also affect diagnosis of anaemia type and related treatment. This can adversely impact on the appropriate use of iron supplementation, which should be avoided in patients with anaemia of chronic illness or inflammation without treatment of the underlying disease (Weiss et al 2019). Treatment may not be effective and may even cause harm in iron overload disorder or renal impairment (Rostoker 2019). 
The occurrence of preoperative anaemia in our study cohort (36.1\%) falls within the reported range of preoperative anaemia from other bowel or colorectal studies, between 22-76\% (Shander et al 2004, Wilson et al 2017). Our results also confirm that patients undergoing bowel surgery with preoperative anaemia are subject to poor surgical outcomes, including increased transfusion rates and hospital LOS, which once again emphasises the importance of adherence to the PBM guidelines.

Of those who were anaemic and received preoperative treatment, $81 \%$ received iron (but only $16.7 \%$ oral iron) and $19.0 \%$ a transfusion. Anaemic patients required more units of blood than the nonanaemic group (2.43 units vs 1.40 units). This mirrors the current evidence base, including a retrospective study in colorectal cancer surgical patients, where anaemia treated with oral iron supplementation reduced the need for perioperative transfusion from $27.4 \%$ to $9.4 \%(\mathrm{p}<0.05)$, compared to those who did not receive any preoperative treatment (Okuyama et al 2005). In our audit, four patients without anaemia received preoperative IV iron. This is clinically inappropriate and puts patients at risk of iatrogenic injury. Unnecessary use of parenteral iron in the non-anaemic population should be discouraged, and this risk can be minimised by appropriate application of PBM principles.

The patient group not screened for preoperative anaemia generally had a shorter LOS than those who were screened ( 8.62 vs. $5.32, \mathrm{p}<0.001)$. While this may seem counterintuitive, it is probable that clinicians know which groups of patients tend to be anaemic, and therefore, more likely to order blood tests in this cohort. However, as the quality of these anaemia assessments was suboptimal, it is unlikely for the anaemia to be resolved prior to surgery, which might explain the increased hospital LOS. The comparison of laboratory parameter screening between our hospital and the 2015 multistate audit suggests potential benefit from improved communication, by surgical leadership teams, to disseminate the importance of differentiating anaemia types, and how appropriate identification and management can improve patient outcomes (DHHSV \& BM 2016). 
In Australia, PBM implementation remains at an early stage. However, a retrospective multisite audit

217 of over 600,000 Western Australian elective surgery patients confirmed that a jurisdiction-wide PBM

218 program can have a positive impact on patient outcomes (reduction of in-hospital mortality odds ratio $0.72)$, reduced blood product utilisation $(41 \%$ reduction in units per admission $(\mathrm{p}<0.001)$, and product-related costs $(\$ 18,507,023$ AUD saved over six years) (Leahy et al 2017). As timely anaemia treatment, particularly preoperative iron supplementation, remains a crucial component of PBM, emphasis should be placed on building a multidisciplinary model to prevent and manage preoperative anaemia. PBM, along with the application of relevant PBM education, audit and feedback interventions, combine to play a crucial role in ensuring patient and medication safety. Restrictive transfusion has also been used by some hospitals, resulting in a dramatic decrease in the proportion of patients transfused without affecting clinical outcomes (Carson et al 2012).

The major limitation of our study is that it took place at a single centre, so the results may not reflect current practice at other healthcare facilities. However, as our patients were drawn from both our public and private hospitals over a three-year period, it increases the generalisability of our findings. As bowel surgery is not the only surgery with high bleeding risk and PBM guidelines apply, we intend to expand our approach to audit a broader range of major surgical procedures. This will allow surgical specialities to review and compare their local performance, increasing ownership of audit findings and encouraging development of tailored strategies to overcome identified practice gaps. Future local audits are essential to maintain quality of practice and guide hospital feedback activities. At our institution, a newly formed multidisciplinary program of quality improvement will act as a resource for future activities. Our study failed to demonstrate preoperative iron treatment (oral or IV) was associated with reduced hospital LOS or units of blood transfused. However, the treated groups appeared to have a lower rate of transfusion (OR:0.226, $\mathrm{p}=0.002)$. 
241 In conclusion, our PBM bowel surgery audit contributes to contemporary Australian evidence on the

242 clinical impact of preoperative anaemia screening and treatment. It highlights that patients undergoing

243 bowel surgery are at moderate risk of being anaemic, risk transfusion and an extended hospital LOS.

244 Moreover, the current practice around preoperative anaemia screening and subsequent treatment

245 remains suboptimal. It appears there is still a sizeable gap between the recommended Australian PBM

246 guidelines and current practice.

247

248 Acknowledgement

249 The authors acknowledge Dr Cameron Hurst (QIMR Berghofer Medical Research Institute) for his assistance with statistic advice.

251

252 Author contribution

253

EP, AD, DP \& TM contributed to the study design. EP, AD \& LA reviewed the patient selection

254 criteria. EP conducted the audits. EP, AD, DP \& TM contributed to analysis and interpretation of results. All authors contributed to review of results and the final manuscripts.

256

257

Funding

258

The Authors received no financial support for the research, authorship, and/or publication of this

259 article.

260

261

Declaration of Conflicting Interests

262

The Authors declare that there is no conflict of interest. 
Australian Commission on Safety and Qualty in Health Care 2017 National safety and quality health service standards 2nd edn ACSQHC Available from:

https://www.safetyandquality.gov.au/publications-and-resources/resource-library/national-safety-andquality-health-service-standards-second-edition

Baird-Gunning J, Bromley J 2016 Correcting iron deficiency Australian Prescriber 39 (6) 193-199

Benchimol EI, Smeeth L, Guttmann A et al 2015 The REporting of studies Conducted using Observational Routinely-collected health Data (RECORD) Statement PLoS Medicine 12 (10) e1001885

Carson JL, Carless PA, Hebert PC 2012 Transfusion thresholds and other strategies for guiding allogeneic red blood cell transfusion Cochrane database of systematic reviews 4 (4) CD002042CD002042

Chen YJ, Lim C, McCormick J 2019 Resistant iron-induced hypophosphatemia following colorectal surgery New Zealand Medical Journal 132 (1499) 72-75

Delaforce A, Duff J, Ralph N 2018 Changing the standard of blood management in Australia: An overview Journal of Perioperative Nursing 31 (2) 17-19

Department of Health and Human Services Victoria, Blood Matters 2016 Clinical audit of preoperative anaemia assessment and management in elective surgical procedures 2015 report Available from: https://www2.health.vic.gov.au/about/publications/researchandreports/clinical-auditof-preoperative-anaemia-assessment-and-management-2015

Girelli D, Ugolini S, Busti F, Marchi G, Castagna A 2018 Modern iron replacement therapy: clinical and pathophysiological insights International Journal of Hematology 107 (1) 16-30

Goel R, Patel EU, Cushing MM et al 2018 Association of Perioperative Red Blood Cell Transfusions With Venous Thromboembolism in a North American Registry JAMA Surg 153 (9) 826-833

Harris RE, Garrick V, Curtis L, Russell RK 2018 Skin staining due to intravenous iron extravasation in a teenager with Crohn's disease Archives of Disease in Childhood archdischild-2018-316405.

Hong FS, Sieradzki N, Pollock C et al 2018 Correcting preoperative iron deficiency as part of patient blood management in the 'real world': results of an audit on an Australian cohort ISBT Science Series 13 (2) 165-170

Khanna MP, Hebert PC, Fergusson DA 2003 Review of the clinical practice literature on patient characteristics associated with perioperative allogeneic red blood cell transfusion Transfusion Medicine Reviews 17 (2) 110-119

Leahy MF, Hofmann A, Towler S et al 2017 Improved outcomes and reduced costs associated with a health-system-wide patient blood management program: a retrospective observational study in four major adult tertiary-care hospitals Transfusion 57 (6) 1347-1358 
Leal-Noval SR, Muñoz Gómez M, Asuero M et al 2013 Spanish consensus statement on alternatives to allogeneic blood transfusion: the 2013 update of the 'Seville Document' Blood Transfusion 585610

Madrazo-González Z, García-Barrasa A, Rodríguez-Lorenzo L, Rafecas-Renau A, Alonso-Fernández G 2011 Anemia and transfusion therapy: an update Medicina Intensiva 35 (1) 32-40

Michailidou M, Nfonsam VN 2018 Preoperative anemia and outcomes in patients undergoing surgery for inflammatory bowel disease American Journal of Surgery 215 (1) 78-81

Muñoz M, Acheson AG, Bisbe E et al 2018 An international consensus statement on the management of postoperative anaemia after major surgical procedures Anaesthesia 73 (11) 1418-1431

National Blood Authority Australia 2012 Patient blood management guidelines: Module 2 -

Perioperative Available from: https://www.blood.gov.au/pbm-module-2 [Accessed September 2019]

Okuyama M, Ikeda K, Shibata T, Tsukahara Y, Kitada M, Shimano T 2005 Preoperative iron supplementation and intraoperative transfusion during colorectal cancer surgery Japanese Journal of Surgery 35 (1) 36-40

Rostoker G 2019 When should iron supplementation in dialysis patients be avoided, minimized or withdrawn? Seminars in Dialysis 32 (1) 22

Shander A, Knight K, Thurer R, Adamson J, Spence R 2004 Prevalence and outcomes of anemia in surgery: a systematic review of the literature American Journal of Medicine 116 Suppl 7A 58s-69s

Shander A, Van Aken H, Colomina MJ et al 2012 Patient blood management in Europe British Journal of Anaesthesia 109 (1) 55-68

Society for the Advancement of Blood Management 2019 Patient blood management programs [online] Available from: https://www.sabm.org/patient-blood-management-programs/ [Accessed August 2019]

Weiss G, Ganz T, Goodnough LT 2019 Anemia of inflammation Blood 133 (1) 40-50

Weiss G, Goodnough LT 2005 Anemia of chronic disease New England Journal of Medicine 352 (10) 1011-1023

Wilson MJ, Dekker JWT, Harlaar JJ, Jeekel J, Schipperus M, Zwaginga JJ 2017 The role of preoperative iron deficiency in colorectal cancer patients: prevalence and treatment International Journal of Colorectal Disease 32 (11) 1617-1624 


\begin{tabular}{|c|c|c|c|c|c|c|}
\hline & $\begin{array}{l}\text { All patients } \\
\qquad(\mathrm{n}=\mathbf{5 5 9})\end{array}$ & $\begin{array}{l}\text { Anaemic } \\
\text { Patients } \\
(n=167)\end{array}$ & $\begin{array}{l}\text { Non- } \\
\text { anaemic } \\
\text { Patients } \\
(n=295)\end{array}$ & $\begin{array}{c}\text { Patients } \\
\text { without } \\
\text { evidence of } \\
\text { preoperative } \\
\text { screening } \\
(n=97)\end{array}$ & $\begin{array}{l}\text { Public } \\
\text { patients } \\
(n=183)\end{array}$ & $\begin{array}{l}\text { Private } \\
\text { patients } \\
(n=376)\end{array}$ \\
\hline Male:Female (n:n) & $258: 301$ & $79: 88$ & $135: 160$ & $44: 53$ & 74:109 & 184:192 \\
\hline Age (mean) & 59.86 & 63.17 & 59.3 & 55.84 & 57.33 & 61.09 \\
\hline \multicolumn{7}{|l|}{ Principal diagnosis $(\mathrm{n}, \%)$} \\
\hline Bowel disease & $57(10.2 \%)$ & $11(6.6 \%)$ & $30(10.2 \%)$ & $16(16.5 \%)$ & $23(12.6 \%)$ & $34(9.1 \%)$ \\
\hline Bowel neoplasm & $350(62.6 \%)$ & $114(68.2 \%)$ & $183(62.0 \%)$ & $53(54.6 \%)$ & $125(68.3 \%)$ & $225(59.8 \%)$ \\
\hline $\begin{array}{r}\text { Inflammatory/infective } \\
\text { bowel disease }\end{array}$ & $129(23.1 \%)$ & $37(22.2 \%)$ & $72(24.4 \%)$ & $20(20.6 \%)$ & $32(17.5 \%)$ & $97(25.8 \%)$ \\
\hline $\begin{array}{l}\text { Ileostomy \& colostomy } \\
\text { for non-malignant disease }\end{array}$ & $23(4.1 \%)$ & $5(3.0 \%)$ & $10(3.4 \%)$ & $8(8.3 \%)$ & $3(1.6 \%)$ & $20(5.3 \%)$ \\
\hline
\end{tabular}


Total patient $(n=559)$

Total number of patients screened

Time of assessment prior to surgery

$$
\begin{array}{r}
0-1 \text { day } \\
2-6 \text { days } \\
1 \text { week up to } 6 \text { weeks } \\
6 \text { weeks and greater }
\end{array}
$$

Blood test performed

$$
\begin{array}{r}
\text { FBC } \\
\text { Ferritin } \\
\text { Folate } \\
\text { B12 } \\
\text { CRP } \\
\text { Renal function }
\end{array}
$$

Screening results

$$
\text { Anaemic }
$$

Non-anaemic

Anaemia classification

Undifferentiated anaemia

Iron deficiency anaemia

Iron deficiency

Anaemia of inflammation/chronic disease

$$
462(82.6 \%)
$$

Of those assessed $(n=462)$

$$
\begin{aligned}
& 186(40.3 \%) \\
& 124(26.8 \%)
\end{aligned}
$$

$134(29.0 \%)$

$18(3.9 \%)$

Of those assessed $(n=462)$

$$
459(99.4 \%)
$$

$51(11.0 \%)$

$16(3.5 \%)$

$16(3.5 \%)$

$92(19.9 \%)$

$439(95.0 \%)$

Of those assessed $(n=462)$

$167(36.1 \%)$

$295(63.9 \%)$

Of those anaemic $(n=167)$

$147(88.0 \%)$

$8(4.8 \%)$

$2(1.2 \%)$

$10(6.0 \%)$ 
357

358 


\begin{tabular}{|c|c|c|c|}
\hline & $\begin{array}{c}\text { Anaemic patients } \\
(\mathrm{n}=167)\end{array}$ & $\begin{array}{c}\text { Non-anaemic } \\
\text { patients }(n=295)\end{array}$ & $\begin{array}{l}\text { All patients } \\
\qquad(\mathrm{n}=559)\end{array}$ \\
\hline Received treatment & $42(25.2 \%)$ & $7(2.4 \%)$ & $51(9.1 \%)^{*}$ \\
\hline \multicolumn{4}{|l|}{ Types of treatment received } \\
\hline Oral iron & $7(16.7 \%)$ & $3(42.9 \%)$ & $12(23.5 \%)$ \\
\hline Intravenous iron & $27(64.3 \%)$ & $4(57.1 \%)$ & $31(60.8 \%)$ \\
\hline Preoperative transfusion & $8(19.0 \%)$ & $0(0 \%)$ & $8(15.7 \%)$ \\
\hline
\end{tabular}


Table 4. Postoperative outcomes comparing different groups

\begin{tabular}{lccc}
\hline & $\begin{array}{c}\text { Anaemic patients } \\
(\mathbf{n}=\mathbf{1 6 7})\end{array}$ & $\begin{array}{c}\text { Non-anaemic } \\
\text { patients (n=295) }\end{array}$ & p-value \\
\hline Mean hospital LOS (days) & 9.93 & 7.88 & $\mathrm{p}<0.001$ \\
Number of patients transfused & $42(25.1 \%)$ & $5(1.7 \%)$ & OR: 3.186, \\
perioperatively & & & $\mathrm{p}=0.049$ \\
Mean unit of blood transfused & 2.43 & 1.40 & $\mathrm{p}=0.36$ \\
\hline
\end{tabular}

363

364 
Audit

AMTHF 2019 audit

Blood Matters 2015 audit

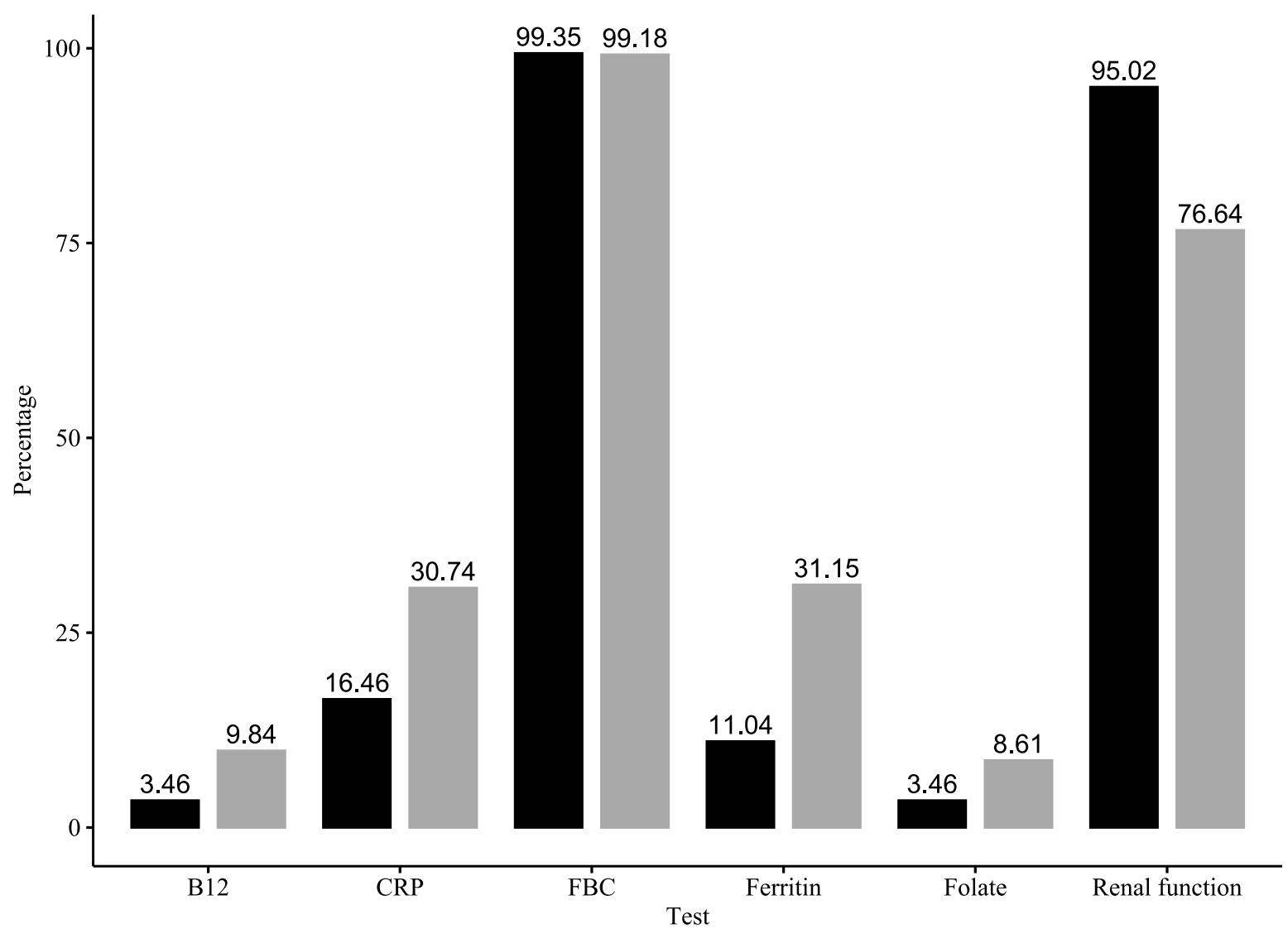

366 Figure 1. Bar graph comparing screening laboratory parameters for two audits: Australian metropolitan teaching healthcare facility (AMTHF) and Australian 'Blood Matters' 2015 audits

368 (DHHSV \& BM 2016). *Blood Matters audit data used with permission 
Impact of anaemia status on hospital length of stay

Strata — Non-anaemic patients - - Anaemic patients

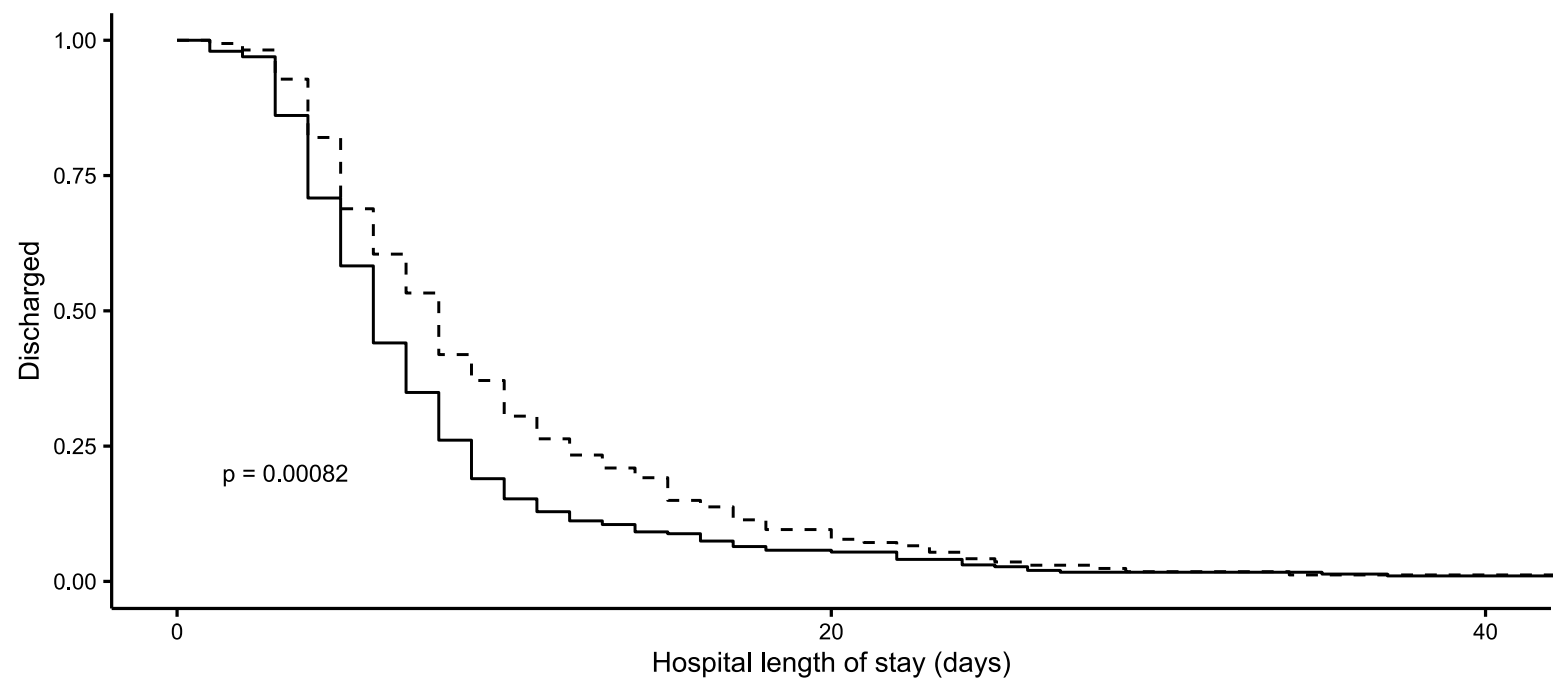

371 Figure 2. Impact of anaemia status on hospital length of stay

372 Key: $0.5=50 \%$ of the patients remain admitted. 


\begin{tabular}{|c|c|}
\hline Patient details & $\begin{array}{l}\text { - } \text { Patient record number } \\
\text { - } \text { Age, Gender } \\
\text { - } \text { Principal diagnosis } \\
\text { clotting risk e.g. inflammatory bowel disease, heart failure, } \\
\text { ischaemic heart disease, chronic renal failure, haematological } \\
\text { malignancy, haemoglobinopathy that requires regular } \\
\text { transfusion }\end{array}$ \\
\hline $\begin{array}{l}\text { Pre-surgical assessment for } \\
\text { anaemia or bleeding risk }\end{array}$ & $\begin{array}{l}\text { Was the patient assessed? If yes: } \\
\text { - Time of assessment prior to surgery } \\
\text { - Which blood tests results were available, specifically: vitamin } \\
\mathrm{B}_{12}, \mathrm{C}-\mathrm{reactive} \text { protein (CRP), folate, full blood count (FBC), } \\
\text { iron studies including ferritin and renal function } \\
\text { - Screening results (anaemic vs non-anaemic) and anaemia } \\
\text { classification } \\
\text { - Whether the available blood test results indicated that treatment } \\
\text { was required } \\
\text { Based on haematological values, whether treatment was required } \\
\text { Wassessment in accordance with the PBM Guidelines? }\end{array}$ \\
\hline Surgical details & $\begin{array}{l}\text { - } \text { Surgical diagnosis related group (DRG) } \\
\text { - } \quad \text { Surgical team } \\
\text { - } \quad \text { Surgery conducted in a public or private hospital }\end{array}$ \\
\hline Hospital length of stay (LOS) & - $\quad$ Number of days \\
\hline Pre-operative treatment & $\begin{array}{l}\text { Was treatment provided? If yes specify: } \\
\text { - Oral iron (dose, frequency of administration) } \\
\text { - Intravenous iron (dose, rate, frequency of administration) }\end{array}$ \\
\hline
\end{tabular}




\begin{tabular}{|c|c|}
\hline & $\begin{array}{l}\text { - Transfusion } \\
\text { Was treatment in accordance with PBM Guidelines? }\end{array}$ \\
\hline $\begin{array}{l}\text { Contraindications to } \\
\text { intravenous iron? }\end{array}$ & $\begin{array}{l}\text { - Known hypersensitivity, atopic allergies, fluid overload, acute } \\
\text { renal dysfunction, hepatic impairment, infection, iron overload, } \\
\text { sodium restriction, uncontrolled hyperparathyroidism }\end{array}$ \\
\hline $\begin{array}{l}\text { Reassessment after treatment } \\
\text { and before surgery (blood } \\
\text { tests)? }\end{array}$ & $\begin{array}{l}\text { - Was the patient reassessed? If yes: } \\
\text { - Was the patient optimised according to the PBM guidelines i.e. } \\
\mathrm{Hb}>130 \mathrm{~g} / \mathrm{L} \text { (male) or } \mathrm{Hb}>120 \mathrm{~g} / \mathrm{L} \text { (female) }\end{array}$ \\
\hline $\begin{array}{l}\text { Comparison of post-operative } \\
\text { outcomes in anaemic vs non- } \\
\text { anaemic groups }\end{array}$ & $\begin{array}{l}\text { - } \text { Mean LOS } \\
\text { - } \quad \text { Number of patients transfused perioperatively } \\
\text { - Mean unit(s) of blood transfused }\end{array}$ \\
\hline Postoperative treatment & $\begin{array}{l}\text { Was postoperative treatment provided? If yes: } \\
\text { - Transfusion and number of units } \\
\text { - Was the transfusion clinically appropriate } \\
\text { - Discharged on oral iron }\end{array}$ \\
\hline
\end{tabular}

